\title{
ARANDELA TRINDADE: Ponto de partida para o aprimoramento lumínico da igreja Santa Rita de Cássia, Rio Tinto - PB
}

\author{
WREATH TRINDADE: Starting point for the luminous improvement of the church Santa \\ Rita de Cássia, Rio Tinto - PB
}

OLIVEIRA FILHO, Edson Queiroz; Bacharel em Design, Universidade Federal da Paraíba, Brasil. edsonqueirozld@gmail.com

\begin{abstract}
Resumo
A luz é uma poderosa ferramenta para ressignificação da percepção. O estudo da iluminação da igreja Santa Rita de Cássia, em Rio Tinto - PB, objetiva desenvolver uma luminária para nave central do templo. Sua atual iluminação compromete o entendimento formal da edificação não contribuindo para preservação do patrimônio histórico cultural. Buscou-se, considerando a metodologia Lobach (2001), analisar a percepção da iluminação local, como também, necessidades estéticas, simbólicas e técnicas. O mapeamento dos equipamentos lumínicos revelou desconformidades técnicas, desconforto visual e alto consumo energético. Nesse sentido, projetouse, de maneira mais sustentável e econômica, a Arandela Trindade para substituir as lâmpadas e equipamentos lumínicos atualmente usados na nave central considerando o "estilo manchesteriano" e seus elementos em Art Déco. A luminária traz simbolismos cristãos, estrutura formal e harmônica. Os objetivos desta pesquisa foram alcançados, porém as melhorias apresentadas são apenas o ponto de partida para o aprimoramento lumínico de toda a edificação.
\end{abstract}

Palavras Chave: Aprimoramento Lumínico; Arandela; Iluminaçao;.

\begin{abstract}
Lighting is a powerful tool to redefine perception. The study of the lighting of the Santa Rita de Cássia church in Rio Tinto - PB aims at developing a luminary for the central nave of the temple. Its current lighting compromises the formal understanding of the building and does not contribute to the preservation of the cultural historical patrimony. The Lobach (2001) methodology was used to analyze the perception of local lighting, as well as its aesthetic, symbolic and technical needs. The mapping of light equipment revealed technical discomforts, visual discomfort and high energy consumption. As such, the Arandela Trindade was designed in a more sustainable and economic way to replace the light bulbs and lighting equipment currently used in the central nave, considering the "Manchester style" and its elements in Art Deco. The lamp brings Christian symbolism, formal and harmonic structure. The objectives of this research were achieved, but the improvements presented are only the starting point for the lighting improvement of the whole building.
\end{abstract}

Keywords: Luminous Enhancement; Wreath; Lighting. 


\section{Introdução}

A necessidade humana de executar tarefas após o pôr do Sol, nos obrigou a buscar maneiras de iluminar nossos espaços com fontes alternativas. Após séculos de evoluções na maneira de iluminar e das tecnologias que impulsionaram novas fontes de luz, a preocupação com a quantidade ainda se mostra mais ativa que o equilíbrio com a qualidade da iluminação.

Por muito tempo acreditou-se que a quantidade de luz propiciava uma boa iluminação do espaço, porém um projeto luminotécnico bem equilibrado visa harmonizar os aspectos quantitativos e qualitativos, podendo variar de acordo com os materiais, culturas, atividades específicas e predileções individuais ou coletivas (DERZE, 2014; CYPRIANO, 2013; ELOY, 2014; NASCIMENTO, 2014).

A iluminação em patrimônio histórico possui intenso poder transformador, não se restringindo aos aspectos formais do monumento, pois este exerce papel fundamental para a preservação da história de um povo, local, cultura e hábitos da população onde a edificação está localizada (CYPRIANO, 2013).

A igreja Santa Rita de Cássia, localizada na cidade de Rio Tinto, Paraíba, possui majestosa arquitetura "manchesteriana" industrial e influência formal de Art Déco. Construída em tijolos aparentes, o templo é imponente à luz do Sol e inglório ao cair da noite, pois, devido à má iluminação, a percepção externa é bastante prejudicada. Já em seu interior a má iluminação peca por excesso, causando desconforto visual (LEHMKUHL; SILVA, 2016).

Em observação, in loco, percebe-se que sua imponência arquitetural se esconde ao fim do dia quando a luz solar dá espaço à iluminação pública, além da deficiente iluminação de destaque da própria Igreja. Os elementos arquitetônicos externos são exaltados sem preocupação com o desenho de suas formas e função espacial. Em seu interior, a nave central é iluminada artificialmente de forma quantitativa por lâmpadas fluorescentes, deixando em segundo plano a qualidade da iluminação, conforto e bem-estar dos frequentadores do templo.

Este trabalho visou projetar um produto de iluminação que auxilie a instalação de um projeto luminotécnico adequado à Igreja Sta. Rita de Cássia, contudo o templo necessita de equipamentos lumínicos aparentes em harmonia com o "estilo manchesteriano" e seus elementos em Art Déco, com isso, haverá congruência das formas e consequentemente unidade visual do ambiente. Esta questão visa valorizar o espaço construído, bem-estar dos frequentadores e resgate cultural histórico.

\section{Desenvolvimento}

A luz natural é, foi e tem sido considerada como a principal fonte de luz para arquitetura, e a variação do seu emprego está diretamente conectada a critérios sócio culturais e ambientais. A luz esteve presente no interior e exterior das residências, templos, rituais e representações políticas, mostrando assim sua importância e influência nas ações humanas (CYPRIANO, 2013).

No entanto, após a descoberta da energia elétrica e os avanços lumínicos, a iluminação 
artificial conquistou profundamente a arquitetura, como podemos identificar na Figura 1 abaixo. Ambas proporcionando compreensão distintas de um mesmo elemento no meio urbano, como corrobora Bahamón (2010, apud NASCIMEMENTO, 2014, p. 4).

Figura 1 - Igreja Santa Rita de Cássia (diurna e noturna)

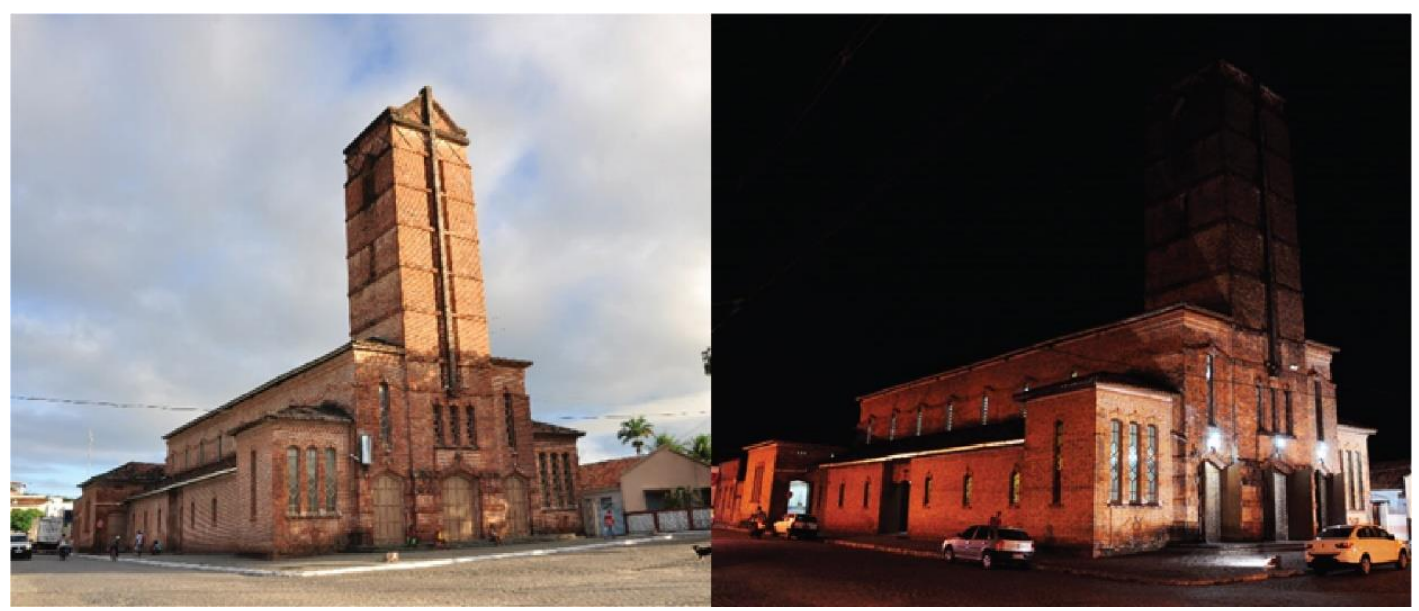

Fonte: Silva (2016); Autor (2017)

Espaços dedicados a cultos e cerimônias religiosas necessitam de um cuidado e atenção específicos, visto que rogam por uma iluminação que proporcione recolhimento, privacidade e introspecção (CYPRIANO, 2013). Por sua vez, Lima (2010) também ressalta cuidados ao iluminar edifícios históricos, buscando intervenções harmoniosas, afim de não contrastar com a arquitetura original e tornar o projeto coeso.

A pesquisa em questão classifica-se quanto aos seus objetivos como de abordagem projetual, pois esta modalidade de investigação objetiva maior aproximação com o problema e aprimoramento de ideias, possibilitando a análise de diversos aspectos a partir da flexibilidade de planejamento, assim como os procedimentos técnicos utilizados neste estudo se classificam em bibliográfico, documental e estudo de campo (LÖBACH, 2001).

A propositura deste tipo de pesquisa deve-se à construção histórica da cidade de Rio tinto PB pelo Grupo Lundgrem, pois, até os dias atuais, os documentos referentes às edificações deste município, em especial a Igreja Sta. Rita de Cássia, estão em posse desta linhagem.

Assim, utilizou-se a metodologia projetual clássica do teórico Bernd Löbach (2001), pois em sua visão, todo o processo de design é tanto um processo criativo como um processo de solução de problemas. Este método é composto por quatro fases (Preparação, Geração, Avaliação e Realização), e cada momento é subdividido em pontos chave, possibilitando uma melhor compreensão do problema e solução satisfatória em forma de produto.

Na primeira fase (Preparação) foi realizada a coleta de informações acerca do ambiente da pesquisa. Este procedimento iniciou-se com a aplicação e análise de um questionário submetido aos frequentadores do templo para identificar seus perfis e percepções sobre o ambiente iluminado.

Após a aplicação do questionário, constatou-se que, no que versa sobre a iluminação interna 
noturna, mais de $50 \%$ dos entrevistados consideram regular, mas uma parcela significativa, 21,95\%, dos frequentadores da nave central estão insatisfeitos com a iluminação oferecida pela igreja. Por outro lado, a maior insatisfação está sobre a iluminação externa, em que pelo menos $75 \%$ dos entrevistados estão insatisfeitos com a iluminação presente na edificação.

Buscou-se também conhecimento dos arquivos e documentos sobre a construção e conservação do templo, que infelizmente, não se encontram no local. Os funcionários da Igreja informaram que a edificação pertence ao Grupo Lundgren, mas é cedido à Arquidiocese da Paraíba para a celebração dos cultos.

Assim foram feitas três visitas à administração do Grupo Lundgren, localizada na Rua da Mangueira, no 18, centro em Rio Tinto, Paraíba, nos dias 17 e 31 de agosto e 5 de setembro de 2017, na tentativa de examinar a planta baixa e outros possíveis documentos da edificação. Novamente não houve êxito, pois a funcionária alegou que o arquivo ainda não havia sido organizado. Logo, para não prejudicar o entendimento técnico formal da edificação, foi produzido pelo próprio pesquisador uma planta baixa com medidas aproximadas da edificação.

Sentiu-se ainda a necessidade de fotografar a edificação, em seu interior e exterior, para uma melhor compreensão acerca da quantidade e qualidade de luz no ambiente, assim como identificar os equipamentos lumínicos e lâmpadas presentes na iluminação do monumento, conforme podemos observar na Figura 2.

Figura 2 - Equipamentos lumínicos e lâmpadas da nave central e altar

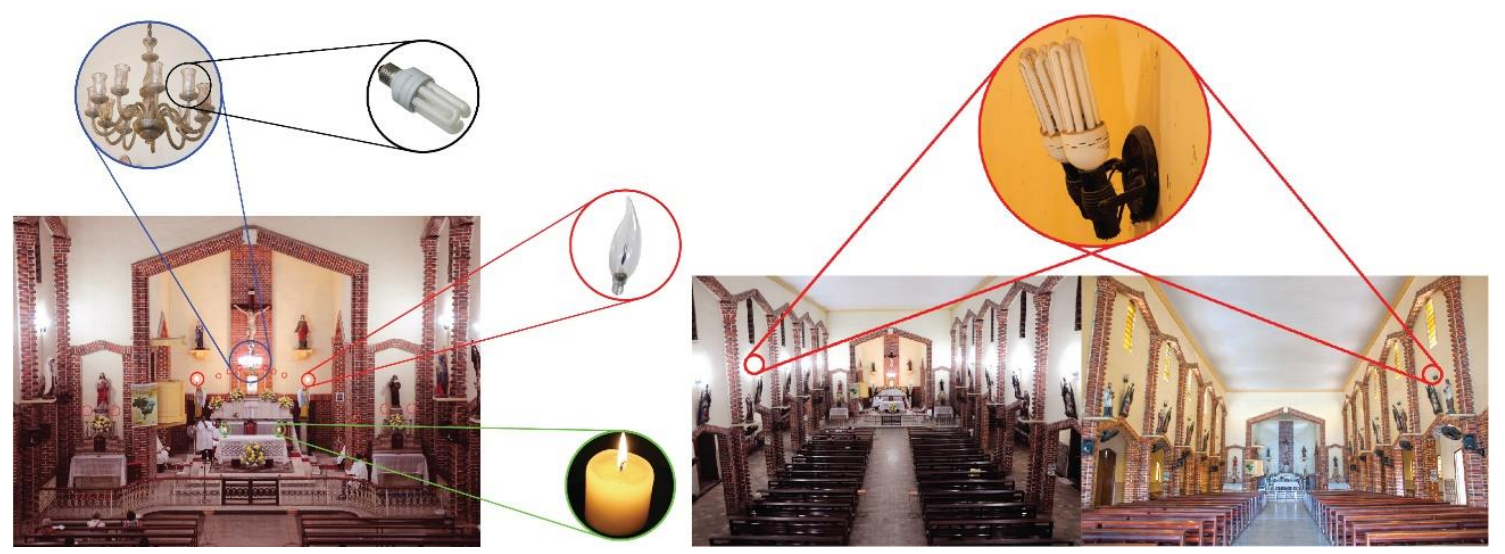

Fonte: Autor (2017)

Assim pudemos calcular, através de simulador de consumo energético, que vinte e oito lâmpadas fluorescentes $4 U$ de luz branca, com potência de $40 \mathrm{~W}$ que são utilizadas 4 horas por dia (das $17 \mathrm{hrs}$ às $21 \mathrm{hrs}$ ), têm consumo de $134.4 \mathrm{~kW} / \mathrm{h}$, gerando custo mensal de $\mathrm{R} \$ 127,33$ (cento e vinte e sete reais e trinta e três centavos) (ENERGISAS, 2017).

Contudo, no altar, encontrou-se significativa variedade lumínica devido aos diversos tipos de lâmpadas, luminárias e suas atribuições simbólicas, estéticas e funcionais, calculando assim que onze lâmpadas fluorescentes compactas $3 \mathrm{U}$, com potência de $10 \mathrm{~W}$, têm consumo de $15.428 \mathrm{~kW} / \mathrm{h}$, gerando custo mensal de $R \$ 13,73$ (treze reais e setenta e três centavos); somados a treze lâmpadas Vela Chama filamento LED de $2 \mathrm{~W}$, tem consumo de $3,04 \mathrm{~kW} / \mathrm{h}$, gerando custo mensal de $\mathrm{R} \$ 2,74$ 
(dois reais e setenta e quatro centavos). Os cálculos acima foram baseados na utilização de 4 horas por dia (das 17hrs às 21hrs) (ENERGISA, 2017).

Ainda no altar, encontram-se dois refletores de alumínio fundido Spotlux, com dimensões $365 \times 275 \times 165 \mathrm{~mm}$ que comportam, individualmente, uma lâmpada fluorescente $4 \mathrm{U}$ de luz branca e 40W, adicionando o consumo de 9,6kW/h, gerando custo mensal de $\mathrm{R} \$ 9,09$ (nove reais e nove centavos). Assim o consumo energético total do altar é de $28,068 \mathrm{~kW} / \mathrm{h}$, gerando custo total mensal de $R \$ 25,56$ (vinte e cinco reais e cinquenta e seis centavos) (ENERGISA, 2017).

As laterais da nave central e do altar, juntamente com a entrada da igreja, apesar de não fazerem parte do objeto desta pesquisa, integram o ambiente. Assim, também foram identificados seus equipamentos lumínicos e lâmpadas.

$\mathrm{Na}$ entrada principal existem três luminárias brancas, fabricante RCG, modelo Centaurus, $11,5 \mathrm{~cm}$ de altura, $9,6 \mathrm{~cm}$ de largura, $70 \mathrm{~cm}$ de comprimento, $1,5 \mathrm{Kg}$ de peso, que comportam duas lâmpadas fluorescentes tubulares T8 de $20 \mathrm{~W}$, com cor de luz branca, temperatura de cor $6.000 \mathrm{~K}$, IRC 80 , eficiência luminosa de $1.600 \mathrm{~lm} / \mathrm{W}$, com durabilidade média de 8.000 horas. Nas laterais da nave central e laterais do altar, existem quatro luminárias do mesmo modelo por lado, totalizando 38 lâmpadas T8. Tomando como base de cálculo 4 horas por dia (das $17 \mathrm{hrs}$ às $21 \mathrm{hrs}$ ), o consumo é de $91,2 \mathrm{~kW} / \mathrm{h}$, gerando custo mensal de $\mathrm{R} \$ \mathbf{8 1 , 1 7}$ (oitenta e um reais e dezessete centavos) (ENERGISA, 2017; LEROYMERLIN, 2017).

Após somar todos os valores de consumo presentes no interior do templo, constatou-se que o consumo energético total mensal é de $253,66 \mathrm{~kW} / \mathrm{h}$, gerando um custo mensal total de $\mathrm{R} \$ 234,06$ (duzentos e trinta e quatro reais e seis centavos).

Já em seu exterior, a edificação possui 6 refletores do mesmo modelo encontrado no interior do altar. Das lâmpadas utilizadas na iluminação, quatro são lâmpadas fluorescentes $4 U$ de luz branca e 40W, e duas lâmpadas fluorescente de alta pressão de vapor de sódio Constantcolor - CMH tubular clara de $150 \mathrm{~W}$. Possui bulbo T15, 4,8cm de diâmetro, comprimento de $20,9 \mathrm{~cm}$. Exibe temperatura de $4.200 \mathrm{~K}$, IRC 89 , eficiência luminosa de $14.500 \mathrm{Im} / \mathrm{W}$ e vida útil média de 15.000 horas (GELIGHTING, 2015; LEROYMERLIN, 2017).

Pôde-se então calcular que o consumo energético geral mensal do templo nas zonas estudadas é, de $365,26 \mathrm{~kW} / \mathrm{h}$, gerando um custo mensal de $\mathrm{R} \$ 334,03$ (trezentos e trinta e quatro reais e três centavos).

Após análises desses pontos, conclui-se que os frequentadores do altar, por exercerem atividades laborais, necessitam de iluminação mais adequada às suas funções, e, devido à idade dos frequentadores na nave central e por exercerem leituras, também carecem de iluminação mais apropriada (ABNT, 1992; COELHO, 2005; CYPRIANO, 2013).

A iluminação presente no interior da edificação, apesar de considerada regular por cerca de $50 \%$ dos frequentadores, apresenta pouca valorização do espaço e por vezes prejudicando a visualização e entendimento dos elementos que compõe o ambiente. As lâmpadas usadas na nave central estão expostas diretamente aos frequentadores, e localizadas exatamente acima e por trás das representações simbólicas do calvário de Jesus, dificultando a visualização destes signos, causando ofuscamento, reflexos incômodos, sombras e contrastes excessivos, o que é vedado pela NR-17. As luzes encontradas no altar precisam valorizar mais as imagens do ambiente, pois este local abriga as principais referências simbólicas do catolicismo. 
Por sua vez, a iluminação exterior é bem precária, visto que não existe nenhuma preocupação com a quantidade, tampouco com a qualidade da luz incidida sobre a edificação. Os 6 refletores encontrados na parte frontal da igreja estão posicionados de maneira aleatória sem nenhuma preocupação com a valorização estética do templo, utilizando-se de temperatura de cor e potência desproporcionais aos materiais que desenham a igreja em questão. Os refletores posicionados no chão causam ofuscamento profundo de quem passa pela calçada ou está saindo da Igreja. A torre central está tomada pela escuridão devido a ineficiência dos equipamentos e lâmpadas usadas no local.

Acrescenta-se, que o ambiente em questão abriga atividades laborais, como leitura e manuseio de objetos. A Associação Brasileira de Normas Técnicas (ABNT), NBR ISO:CIE 8995-1 (2013), juntamente com a NR-17 (1978) e NBR 5413 (1992), versam sobre a quantidade mínima de iluminação interior em diversos tipos de atividades laborais, principalmente os que realizam tarefas visuais e manuais, visando um ambiente saudável e sem riscos de acidentes.

Na segunda fase traçou-se caminhos e estratégias para solucionar o problema a partir das análises coletadas na etapa anterior através da técnica de brainstorm, buscando assim a produção de um painel visual que impulsionou a definição de conceito e geração de um número expressivo de alternativas. Aliando o método Business Model Canvas, conhecida ferramenta de planejamento estratégico de negócios, apoiando o prosseguimento da projetação do novo produto (LÖBACH, 2001; OSTERWALDER, 2008).

Também nesta etapa construiu-se o conceito do novo produto, o qual possui como esteio a pertinente função social da iluminação, visto que a força modificadora do espaço iluminado vai além do aspecto estético, mas incisivamente na qualidade de vida da cidade e consequentemente da relação indivíduo/ambiente. Para alcançar esta almejada harmonia entre estética e funcionalidade, a iluminação deve atentar para a segurança das pessoas e seus pertences, a estética do ambiente noturno, do ambiente interno, e economia, que varia de acordo com o local e cultura (AURA, 2015; MARTINS, 2011).

A intervenção luminosa deve ser bem planejada e possuir em sua base, de forma consciente, o delineamento do consumo dos recursos energéticos, das possíveis emissões provocadas, da manutenção do sistema e descarte do material após seu tempo de vida útil.

O Light Design exerce papel social fundamental na simbiose entre pessoas e o espaço. 0 devido atendimento das necessidades e expectativas lumínicas, podem levar a uma mudança significativa no sentimento e atitudes da população, estimulando a preservação desses ambientes (AURA, 2015; COELHO, 2005).

O reconhecimento da iluminação como ferramenta social de produção do bem-estar urbano, aumento da qualidade de vida e requalificação da percepção noturna do tempo no espaço, excitando assim o orgulho cívico da população. A iluminação não deve mais ser entendida como privilégio e sim como um direito a todos (AURA, 2015; BRITO, 2004; COELHO, 2005).

Aliado a isto, sentiu-se necessidade da representação simbólica católica devido ao públicoalvo específico. Portanto, buscou no dogma católico o mistério central da fé cristã, a Santíssima Trindade, que significa um só Deus dividido em três pessoas distintas, o pai, o filho e o espírito santo, formando a natureza divina do catolicismo (AKIN, 2013). 
$\mathrm{Na}$ terceira fase foram avaliadas as alternativas geradas seguindo o método de Pareto, na qual apenas $20 \%$ das alternativas geradas seguem para uma avaliação mais criteriosa em concordância com os requisitos e parâmetros amparados pelo conceito. Por seguinte foi feita a escolha da opção mais adequada e incorporadas características ainda em desconformidade com o anteriormente proposto para o novo produto.

Some-se a isso a intensa relação que a luminária terá com o ambiente e seus frequentadores, não devendo ser o objeto de principal atenção do espaço, mas agregador de valor, proporcionador de bem-estar e facilitador das atividades realizadas no local.

A alternativa eleita mais adequada à proposta possui estrutura formal baseada em retas escalonadas adequando-se melhor as influências Art Déco encontrado na igreja; suas formas simples permitem uma estrutura mais leve e boa dissipação da luz, facilitando o controle da luminosidade e ofuscamento de maneira mais eficiente.

A alternativa escolhida foi submetida a mais estudos formais buscando-se refinar suas formas e trazer mais simbolismo à peça, visto que o ambiente religioso católico é rodeado de signos e significados essenciais à fé cristã. Notou-se também que o Art Déco possui muitos ornamentos, molduras geométricas, simétricas e escalonadas, assim produziu-se alternativas que buscassem essa influência agregando os dogmas presentes e praticados pelos frequentadores do templo. Encontrou-se então, na Santíssima Trindade, a referência católica que resultou na peça da Figura 3 abaixo:

Figura 3 - Representação da Santíssima Trindade

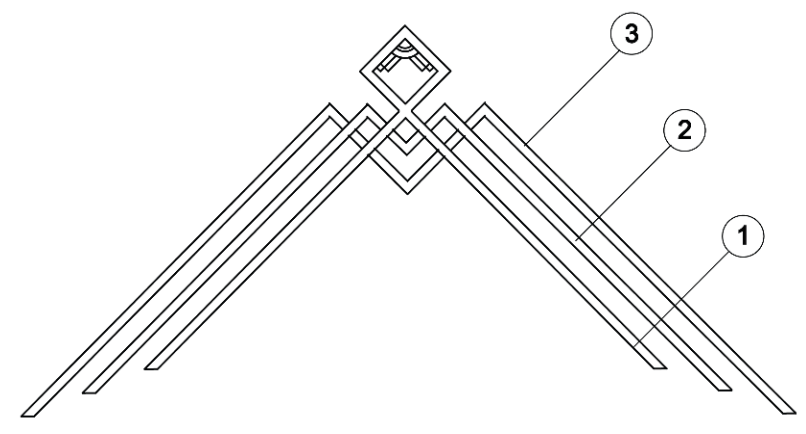

Fonte: Autor (2017)

A tríade basilar é representada pelo Pai (no 3), que gera o filho e por isso encontra-se mais ao fundo, buscando transpassar proteção e plenitude; Filho (no 2), o qual é gerado pelo pai e enviado ao mundo como salvador, encontra-se ao centro, atuando como agente intercessor; e Espirito Santo (no 1), representando o amor de Deus em ação, situando-se à frente como figura comunicadora do criador com sua criação, que podemos observar na Figura 4; e juntos representam a figura central da igreja, Deus (AKIN, 2013).

Por fim, a estrutura formal da luminária complementa-se com um componente circular por traz dos elementos mostrados acima, reafirmando a concepção de divindade através da forma geométrica perfeita, como é entendido Deus pelos cristãos. 
Figura 4 - Arandela Trindade (modelo digital)

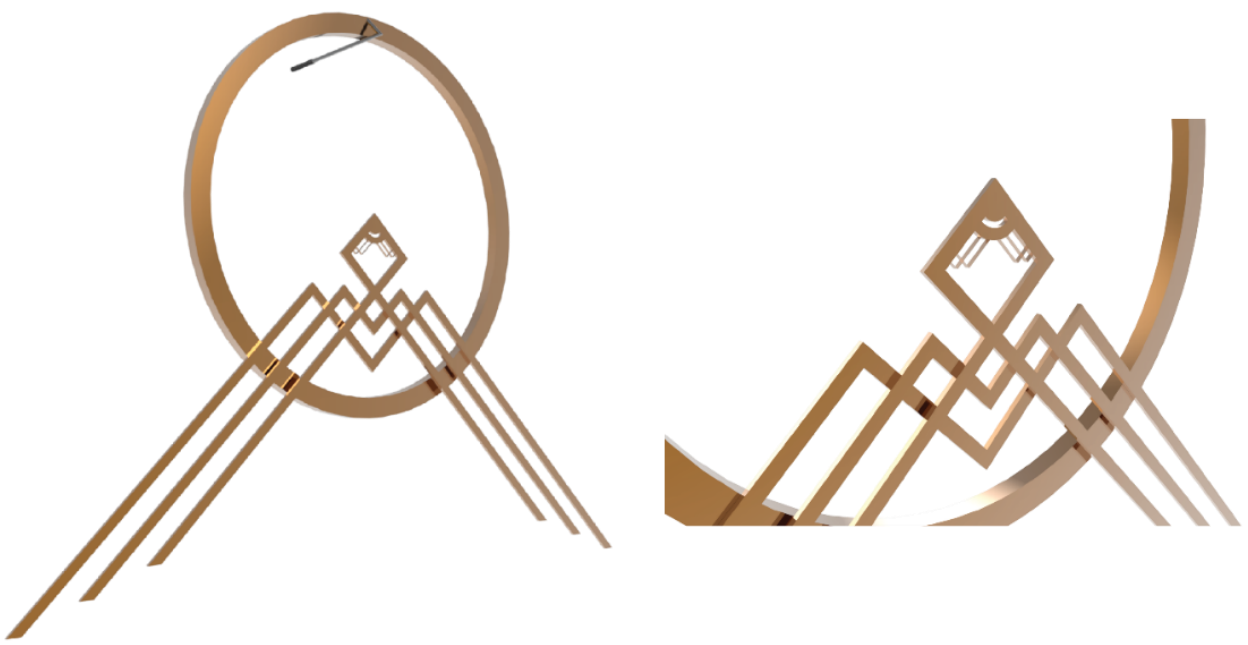

Fonte: Autor (2017)

Nesta quarta fase (Realização) buscou-se a materialização da alternativa na forma de desenhos técnicos e modelos representativos para um melhor entendimento formal do novo produto LOBACH (2001).

O produto desenvolvido a partir desta pesquisa configurou-se em uma arandela (luminária destinada às paredes e estruturas verticais). A peça em questão foi batizada de Arandela Trindade devido a inspiração advinda da Santíssima Trindade, tendo em vista que o ambiente de utilização desta luminária é a igreja católica Sta. Rita de Cássia, localizada na cidade de Rio Tinto - PB.

Suas formas carregam significados católicos e estrutura escalonada, especificamente projetada para constituir harmonia visual no templo em que será instalada e atender as necessidades dos frequentadores e trabalhadores deste ambiente.

A demanda por projetos sustentáveis é essencial para melhoria da qualidade de vida da comunidade, e o designer tem como eixo profissional projetar para solucionar problemas objetivando facilitar a realidade dos viventes. Neste sentido, dentre os vários tipos de fontes de luz existentes no mercado, optou-se pelo LED devido suas características técnicas, por exemplo uma maior eficiência energética, baixo desgaste do fluxo luminoso, maior vida útil, por ser livre de substâncias tóxicas, e vários outros fatores já mencionados nesta pesquisa.

Sob esta visão, a Arandela Trindade possui como fonte de luz uma fita de LED da marca Stella, com potência de $6 \mathrm{~W}$, rendimento médio do fluxo luminoso de $90 \mathrm{~lm} / \mathrm{W}$, temperatura de cor em $3000 \mathrm{~K}$, IRC 80 , consumo energético de $4,8 \mathrm{~W} / \mathrm{m}$, vida útil média de 35.000 horas. A fita luminosa utilizada apresenta dimensões $2 \mathrm{mx} 10 \mathrm{~mm}$, na qual possui 60 LEDs por metro, totalizando 120 partículas emissoras de luz. Em adição, o custo médio é de $R \$ 26,00$ (vinte e seis reais) por metro, necessitando de 01 (uma) fonte para fita LED de 3A com custo médio de $R \$$ 49,90 (quarenta e nove reais e noventa centavos).

Para a substituição completa das 28 lâmpadas fluorescente do ambiente, serão necessárias 14 Arandelas Trindade que comportam $28 \mathrm{~m}$ de fita LED. E comparando-as, nota-se que, em sua totalidade, a substituição de tecnologia promove a duração do tempo vida útil média de 29.000 
horas a mais, consumindo apenas $20,16 \mathrm{~kW} / \mathrm{h}$ mensalmente, refletindo diretamente no custo gerado, de $\mathrm{R} \$ 19,09$ (dezenove reais e nove centavos) por mês. Assim conclui-se que a mudança das fontes de luz fluorescente para LED resulta na redução de consumo energético e economia de $85 \%$.

Esta transição de tecnologia, a partir da Arandela Trindade, também proporcionará transformações estéticas, emocionais benéficas à percepção do ambiente, bem-estar comum e conforto visual para executar as atividades, laborais ou não, no templo. Para isso a fonte lumínica instala-se na seção posterior da base circular do produto, direcionando o feixe de luz para a parede que refletirá a luz para o ambiente de forma indireta, solucionando o problema do ofuscamento causados pelas lâmpadas atuais.

Devido a posição da fonte luminosa na estrutura formal da arandela, forma-se um desenho de luz no entorno da base circular, imprimindo a ideia de divindade representadas pela auréola. A temperatura de cor em 3000k trará aos frequentadores um ambiente mais equilibrado e visualmente confortável. A cor branco quente gerada pela fonte lumínica exalta a arquitetura, exaltando a cor e texturas dos tijolos aparentes da igreja, assim como oportunizando um ambiente mais favorável ao recolhimento e interação com o divino.

A estrutura formal da Arandela Trindade é composta de cinco partes, a base circular que abriga a fonte luminosa, três hastes representando a Santíssima Trindade (Pai, Filho e Espírito Santo) e um pino parafusado de sustentação. O produto é constituído de um único material, latão, e suas peças são produzidas a partir de chapas cortadas e soldadas. O pino parafusado de sustentação, devido sua função, é feito de ferro.

A Arandela Trindade será instalada apenas na nave central do templo, exatamente no lugar em que atualmente se encontram as lâmpadas fluorescente que iluminam o local. Especificamente a 5,30m de altura entre os pilares da edificação, como podemos enxergar na simulação encontrada na Figura 5.

Figura 5 - Arandelas Trindade instaladas (representação virtual)

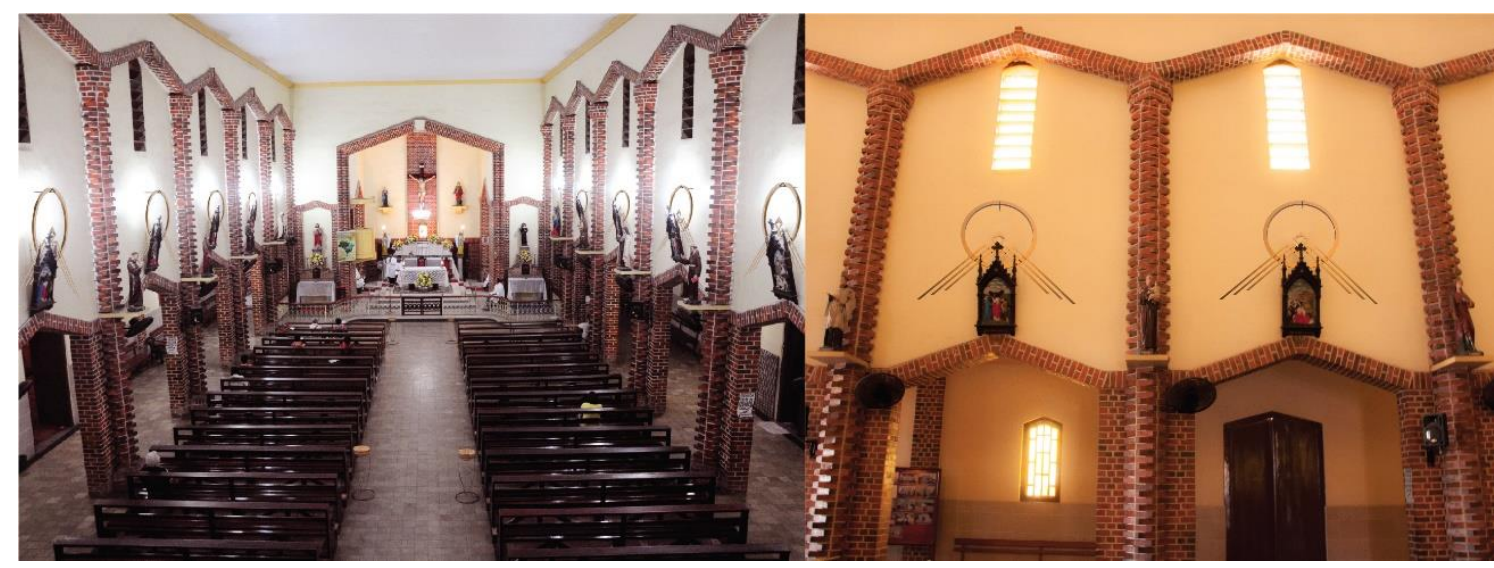

Fonte: Autor (2017) 


\section{Conclusão}

O objeto desta pesquisa centrou-se em analisar a intensa relação da sensação e percepção humana de seu entorno promovida pela iluminação. A luz solar é a principal fonte lumínica, assim como as fontes de luz artificiais são auxiliadoras da compreensão do espaço na falta da primeira. Em outras palavras, o inquestionável poder transformador da iluminação vai além dos aspectos formais, influenciando diretamente no bem-estar humano.

Conclui-se que a má iluminação detectada na igreja Santa Rita de Cássia, não só compromete o entendimento formal da edificação, mas exerce papel contraproducente na preservação do patrimônio histórico cultural da cidade de Rio Tinto. Entende-se assim a urgência em uma intervenção, iniciada a partir do projeto de desenvolvimento de um produto de iluminação para a nave central do templo, que promova a valorização da edificação como parte da identidade da cidade, bem-estar dos frequentadores e resgate cultural histórico. Neste sentido, buscou-se imergir o designer projetista em aspectos físicos, biológicos e sensoriais causados pela interação entre a luz, o ambiente e o ser humano.

O cenário em que a pesquisa se desenvolveu possibilitou a articulação de saberes através da união de escolas artísticas, conhecimentos técnicos e estudo da edificação em benefício do desenvolvimento do produto em questão. Em outras palavras, a imersão no ambiente sacro, com influências da Art Déco e "estilo manchesteriano" industrial, aliados à técnicas de iluminação, respaldaram o esteio influenciador para a projetação formal da Arandela Trindade.

Some-se a isto, como ferramenta projetual principal de pesquisa e execução, a metodologia desenvolvida por Lobach (2001), afim de nortear os procedimentos essenciais ao desenvolvimento do novo produto. As fases do desenvolvimento projetual proporcionaram o entendimento da percepção dos frequentadores e as reais necessidades técnicas e simbólicas do ambiente estudado.

Podemos assim conferir conhecimento a este estudo, como aliados das ferramentas projetuais, as influências formais dos espaços que decorrem a pesquisa. Portanto o diagnóstico das formas para um novo produto, buscam entrar em harmonia com o ambiente e os frequentadores do espaço em que serão inseridos, visto que esta conexão corrobora às análises da relação social (homem-produto), da relação com o ambiente (produto-ambiente) e da configuração das funções estéticas aplicadas na abordagem projetual proposta por Lobach (2001).

Após o mapeamento das lâmpadas e equipamentos lumínicos do ambiente, constatou-se um elevado consumo energético empregado em desconformidade com normas técnicas, causando desconforto aos frequentadores e distorcendo a compreensão formal da arquitetura. Assim desenvolveu-se a Arandela Trindade, que, apropriou-se do Art Déco como ponto central das decisões formais, abarcado de simbolismos cristãos, estrutura formal em harmonia com o ambiente, especificações lumínicas que solucionam os problemas encontrados e atende as necessidades dos frequentadores de forma mais sustentável e econômica.

Conclui-se ainda que os objetivos desta pesquisa foram alcançados, porém as melhorias proporcionadas pela Arandela Trindade são apenas o ponto de partida para um aprimoramento lumínico de toda a edificação. 


\section{Referências}

AKIN, Jimmy. 12 Things to Known and Share About the Holy Trinity. Disponível em: <http://www.ncregister.com/blog/jimmy-akin/12-things-to-know-and-share-about-the-holytrinity>. Acesso em: 02 de outubro de 2017.

ASSOCIAÇÃO BRASILEIRA DE NORMAS TÉCNICAS. NBR 5413: Iluminâncias de Interiores. Rio de Janeiro. 1992. Disponível em:<http://ftp.demec.ufpr.br/disciplinas/TM802/NBR5413.pdf> Acesso em: 24 de agosto de 2017.

AURA LIGHT PORTUGAL. O Papel Social da Iluminação. Revista Produção online. Edição 44. Porto, agosto 2015. Disponível em: <http://www.auralight.pt/wp-content/uploads/2013/08/OElectricista-44_Projecto_2.pdf>. Acesso em: 28 de agosto de 2017.

BRITO, Maria Regina do Nascimento. À Luz dos Monumentos. Rio de Janeiro: Aeroplano, 2004.

COELHO, Luiz Antônio L. Conceitos-chave em Design. Rio de Janeiro: Editora PUC-Rio, 2008.

COELHO, Maria João Pinto. A lluminação Urbana e Ambiental como Instrumento de Valorização das Cidades Históricas. Revista Lapro Fachadas \& Monumentos. Edição 04. São Paulo: De Maio Comunicação e Editora, maio 2005.2 Disponível em: <http://lumearquitetura.com.br/pdf/LA_Pro3/05\%20-\%20pro_fachadas_Internacional.pdf >. Acesso em: 06 de setembro de 2017.

CYPRIANO, Altimar. Iluminação Artificial na Percepção da Arquitetura. Considerações Sobre Aspectos Quantitativos e Qualitativos no Processo de Projeto. 2013. 204 f. Trabalho de Conclusão de Curso (Dissertação). Disponível em: <http://www.teses.usp.br/teses/disponiveis/16/16132/tde29072013-105957/en.php>. Acesso em: 27 de fevereiro de 2017.

DERZE, Farlley. Cidade à Noite: Iluminação Artificial e Modernidade. 2014. 360 f. Trabalho de Conclusão de Curso (Doutorado). Disponível em: <http://repositorio.unb.br/handle/10482/16758>. Acesso em: 27 de fevereiro de 2017.

ELOY, Nereida. A lluminação da Arquitetura Tombada - Com a Abordagem de Monumentos no Centro Antigo de Salvador. Revista Produção online. Edição 1. Salvador: IPOG, dezembro 2014. Disponível

em: <http://www.ipoggo.com.br/uploads/arquivos/4d2b3c86b8396ae0080f6c6d63e840df.pdf>. Acesso em: 27 de fevereiro de 2017.

ENERGISA. Simulado de Consumo. Disponível em: <http://www.energisa.com.br/Paginas/simulador-de-consumo.aspx>. Acesso em: 16 de outubro de 2017.

GELIGHTING. Catálogo de Produtos 2015. Disponível em: <http://www.gelighting.com/LightingWeb/br/images/catalogo-produtos-2015_tcm38890024.pdf>. Acesso em: 18 de outubro de 2017.

GIL, Antonio Carlos. Como Elaborar Projetos de Pesquisa. 5. Ed. São Paulo: Atlas, 2002. Disponível em:

$<$ https://aprender.ead.unb.br/pluginfile.php/232902/mod_resource/content/1/O\%20que\%20\%C3 \%A9\%20pesquisa_0\%20que\%20\%C3\%A9\%20fazer\%20pesquisa\%20\%28Gil.pdf>. Acesso em: 07 de 
maio de 2017.

LEROYMERLIN. Lâmpadas Fluorescentes. Disponível em: <https://www.leroymerlin.com.br/lampada-fluorescente-u-luz-branca-40w-250v--220v-ourolux_88393536>. Acesso em: 16 de outubro de 2017.

LEHMKUHL, Luciente; SILVA, Jeferson Luiz Braz da. A Cidade-fábrica de Rio Tinto na Pesquisa em Design. p. 437-488. In: Anais do 12을 Congresso Brasileiro de Pesquisa e Desenvolvimento em Design. São Paulo: Blucher, 2016. Disponível em: <http://www.proceedings.blucher.com.br/articledetails/a-cidade-fbrica-de-rio-tinto-na-pesquisa-em-design-24274>. Acesso em 12 de agosto de 2017.

LÖBACH, Bernd. Design Industrial: Bases para a Configuração dos Produtos Industriais. 1. ed. São Paulo: Edgard Blücher Ltda., 2001.

MARTINS, Juliana. O Papel Social da Luz Urbana. Revista Produção online. Edição 69. São Paulo: Atitude Editorial, outubro 2011. Disponível em: <https://www.osetoreletrico.com.br/o-papelsocial-da-luz-urbana/>. Acesso em: 28 de agosto de 2017.

NASCIMENTO, Cristhian Augusto Furquim do. Iluminação Artificial e Seu Impacto no Ser Humano: Uma Ferramenta Indispensável aos Arquitetos e Projetistas de Interiores. Revista Produção online. Edição 1. Salvador: IPOG, dezembro 2014. Disponível em: <http://especializandovencedores.com.br/uploads/arquivos/477f6ea7fffa6d8b5e1bba86df2b8067 .pdf>. Acesso em: 27 de fevereiro de 2017.

OSTERWALDER, Alexander. The Business Model Canvas. Disponível em: <http://nonlinearthinking.typepad.com/nonlinear_thinking/2008/07/the-business-modelcanvas.html>. Acesso em: 05 de abril de 2017. 